\title{
STUDI EVALUASI TENTANG PEMBELAJARAN TUNE UP ENGINE PADA SISWA SEKOLAH MENENGAH KEJURUAN BERDASARKAN STANDAR KOMPETENSI KERJA NASIONAL INDONESIA
}

\author{
Muhammad H. Zuhri ${ }^{1}$, Inu H. Kusumah ${ }^{2}$, Ridwan A.M. Noor ${ }^{3}$, Dede Suhayat ${ }^{4}$ \\ Universitas Pendidikan Indonesia \\ J1. Dr. Setiabudhi No. 229 Bandung 40154 \\ zuhri904@gmail.com
}

\begin{abstract}
ABSTRAK
Tujuan penelitian ini adalah untuk mengetahui hasil belajar pada kompetensi tune up engine berdasarkan SKKNI. Metode penelitian yang digunakan yaitu penelitian evaluasi dengan model evaluasi goal oriented evaluation dengan pendekatan deskriftif kuantitatif. Sampel dalam penelitian ini terdiri dari 10 orang siswa kelas XI TKR 5 SMK Negeri 6 Bandung, pemilihan sampel pada penelitian ini berdasarkan pertimbangan dari guru mata pelajaran PMKR dan nilai kompetensi siswa. Hasil penelitian ini adalah : rata-rata hasil ketercapaian kerja tune up engine adalah 37,75, dengan persentase ketercapaian hasil kerja tune up engine dengan nilai tertinggi yaitu $73,2 \%$ dan $71,4 \%$, sedangkan nilai terendahnya adalah $64,28 \%$ dan $62,5 \%$. Perincian ketercapaian tune up engine setiap siswa dengan nilai tertinggi yaitu 40 dan 41 , nilai sedang yaitu 38 dan 39, sedangkan untuk nilai terendah yaitu 35. Pencapaian tune up engine berdasarkan SKKNI yaitu 56, dilihat dari data di atas maka hasil belajar siswa pada kompetensi tune up engine berdasarkan SKKNI menunjukkan hasil yang kurang baik.
\end{abstract}

Kata kunci: evaluasi kinerja, tune up engine, SKKNI, otomotif.

\section{PENDAHULUAN}

Evaluasi (evaluation) diartikan sebagai kegiatan pemberian nilai dan arti. Evaluasi juga berarti mempelajari bagaimana proses pemberian pertimbangan mengenai kualitas sesuatu, gambaran kualitas yang dimaksud merupakan konsekuensi logis dari proses evaluasi yang dilakukan. Proses tersebut tentu dilakukan secara sistematis dan berkelanjutan, dalam arti terencana, sesuai dengan prosedur dan prinsip serta dilakukan secara terus menerus. Evaluasi mempunyai kedudukan yang penting dan strategis karena evaluasi merupakan bagian yang tidak terpisahkan dari pembelajaran (Arikunto dan Jabar, 2010).

Pembelajaran adalah suatu proses atau kegiatan yang sistematis, yang bersifat interaktif dan komunikatif antara pendidik dengan peserta didik, sumber belajar dan lingkungan untuk menciptakan kondisi yang memungkinkan terjadinya tindakan belajar peserta didik, baik di kelas maupun di luar kelas, dihadiri pendidik baik secara fisik atau tidak, untuk menguasai kompetensi yang telah ditentukan (Widoyoko, 2016).

\footnotetext{
${ }^{1}$ Mahasiswa Departemen Pendidikan Teknik Mesin FPTK, UPI

${ }^{2}$ Dosen Departemen Pendidikan Teknik Mesin FPTK, UPI

${ }^{3}$ Dosen Departemen Pendidikan Teknik Mesin FPTK, UPI

${ }^{4}$ Dosen Departemen Pendidikan Teknik Mesin FPTK, UPI
} 
Evaluasi pembelajaran adalah suatu proses atau kegiatan yang sistematis, berkelanjutan, dan menyeluruh dalam rangka pengendalian, penjaminan, dan penetapan kualitas pembelajaran terhadap berbagai komponen pembelajaran berdasarkan pertimbangan dan kriteria tertentu, sebagai bentuk pertanggung jawaban pendidik dalam melaksanakan pembelajaran (Ratnawulan dan Rusdiana, 2015).

Evaluasi pembelajaran adalah serangkaian kegiatan untuk memperoleh, menganalisis dan menafsirkan data tentang proses dan hasil belajar peserta didik yang dilakukan secara sistematis dan berkesinambungan sehingga menjadi informasi yang bermakna dalam pengambilan keputusan dalam mata pelajaran tertentu di sekolah (Arifin, 2013). Berdasarkan fungsinya evaluasi dapat diklasifikasikan menjadi dua bagian, yaitu evaluasi proses dan evaluasi hasil pembelajaran. Evaluasi proses merupakan kegiatan pengukuran yang dilaksanakan secara sistematis untuk memperoleh informasi tentang efektivitas aktifitas belajar mengajar, sedangkan evaluasi hasil belajar menunjuk pada aktifitas penilaian terhadap tingkat kualitas hasil belajar yang dicapai peserta didik. Penilaian hasil dan proses pembelajaran saling berkaitan satu sama lain sebab hasil merupakan akibat dari proses.

Sekolah Menengah Kejuruan (SMK) merupakan program pendidikan kejuruan pada tingkat menengah, yang dalam penyelenggaraannya dimaksudkan untuk mempersiapkan lulusannya guna memasuki dunia kerja sesuai bidang keahlian yang dimiliki yaitu bidang tertentu yang dipelajari ketika proses pendidikan dan pelatihan dilaksanakan di SMK atau melanjutkan ke jenjang yang lebih tinggi. SMK Negeri 6 Bandung merupakan salah satu sekolah menengah kejuruan yang memiliki beberapa kompetensi keahlian dan salah satu kompetensi keahlian yang ada di SMK Negeri 6 Bandung adalah Teknik Kendaraan Ringan (TKR). Kompetensi keahlian TKR terdapat mata pelajaran Pemeliharaan Mesin Kendaraan Ringan. Pembelajaran PMKR menuntut siswa agar memiliki kompetensi untuk melaksanakan pemeliharaan atau perawatan/servis berkala mesin kendaraan ringan, yang meliputi melaksanakan pemeliharaan berkala mesin kendaraan ringan, sistem pelumasan dan pendingin, sistem pengapian, sistem bahan bakar bensin, dan sistem kontrol emisi gas buang.

Hasil observasi di lapangan mengenai evaluasi pembelajaran, diperoleh data bahwa pelaksanaan pembelajaran pemeliharaan mesin kendaraan ringan di SMK Negeri 6 Bandung masih memperlihatkan ketidaksiapan baik personal dan optimalnya pelaksanaan proses pembelajaran. Fakta menunjukkan bahwa hasil belajar siswa kelas XI TKR 5 pada mata pelajaran pemeliharaan mesin kendaraan ringan sebagian besar masih rendah. Hal 
tersebut dapat dilihat dari daftar nilai kompetensi, yaitu sebanyak 60\% siswa tergolong kategori belum tuntas, sedangkan $40 \%$ siswa yang mampu melewati nilai sesuai dengan Kriteria Ketuntasan Minimal (KKM 75). Pada dasarnya, proses pembelajaran pemeliharaan mesin kendaraan ringan lebih bersifat konstruksi pengetahuan dan keterampilan melalui aktifitas berpikir dan pengalaman bersentuhan langsung dengan objek pemeliharaan mesin kendaraan ringan, memperlihatkan keseimbangan antara aspek, teori, praktik, dan personal sosial. Seorang guru juga dituntut lebih meningkatkan profesionalnya dalam pembelajaran sehingga apa yang diinginkan dalam proses pendidikan dapat tercapai dengan maksimal.

Guru yang profesional adalah seorang guru yang terlatih dan terdidik dengan baik serta memiliki pengetahuan yang kaya dibidangnya sehingga mampu memberikan pelayanan dengan optimal pada peserta didiknya, itulah yang dituntut dari seorang guru khususnya dalam pembelajaran pemeliharaan mesin kendaraan ringan di sekolah. Oleh karena itu, diperlukan adanya evaluasi terhadap pelaksanaan pembelajaran pemeliharaan mesin kendaraan ringan di SMK Negeri 6 Bandung, karena dengan adanya beberapa kekurangan dalam pelaksanaan pembelajaran pemeliharaan mesin kendaraan ringan tersebut. Sejauh mana pelaksanaan pembelajaran yang telah dirancang dan apakah siswa dapat menguasai materi yang diberikan oleh guru. Apakah dapat digunakan sebagai tolak ukur untuk melaksanakan pembelajaran pemeliharaan mesin kendaraan ringan yang lebih baik dari sebelumnya.

\section{METODE PENELITIAN}

Penelitian ini menggunakan pendekatan deskriftif dengan metode kuantitatif. Jenis penelitiannya menggunakan jenis penelitian evaluasi. Penelitian evaluasi bertujuan untuk memperoleh informasi yang akurat dan melakukan pengukuran yang cermat terhadap fenomena tertentu, dalam hal ini mendiskripsikan pelaksanaan pembelajaran keterampilan tune up engine pada mata pelajaran pemeliharaan mesin kendaraan ringan pada kelas XI TKR 5 di SMK Negeri 6 Bandung. Model evaluasi yang digunakan yaitu model evaluasi goal oriented evaluation. Model evaluasi yang berorientasi pada tujuan ini cocok diterapkan untuk mengevaluasi program yang jenisnya pemrosesan dalam bentuk pembelajaran. 


\section{HASIL PENELITIAN}

Pengujian instrumen penelitian menggunakan content validity rasio (CVR) dan content validity index (CVI). Hasil pengujian pada instrumen tune up engine memiliki nilai 0.94 yang berarti nilai tersebut menunjukkan bahwa instrumen yang disusun memiliki predikat sangat valid. Perhitungan nilai CVI yang di dapat, instrumen tune up engine yang disusun dinyatakan sangat valid dan dapat digunakan karena memenuhi nilai CVI > 0,67.

Pelaksanaan kegiatan pembelajaran praktik tune up engine dilakukan melalui tiga tahap, yaitu tahap persiapan kerja, proses kerja dan hasil kerja (Bintoro, 2013). Tahap persiapan guru melakukan briefing yaitu menjelaskan keselamatan kerja, menyampaikan peralatan apa saja yang digunakan dalam melaksanakan tune up engine, mengingatkan siswa untuk menjaga kebersihan baik di tempat kerja maupun pada peralatan praktik. Pada tahap proses kerja siswa diminta untuk melaksanakan pekerjaan tune up engine sesuai dengan jobsheet yang ada dan menggunakan workshop manual tentang tune up engine sebagai pedoman. Selain itu, guru membantu siswa yang mengalami kesulitan dalam proses tune up engine dengan cara mendemonstrasikan pekerjaan tune up engine yang dilakukan. Sedangkan untuk hasil kerja yaitu guru melihat hasil pekerjaan tune up engine yang dilakukan siswa pada lembar jobsheet yang telah diisi oleh siswa. Setelah proses pembelajaran tune up engine selesai guru menyimpulkan materi dan menginformasikan materi selanjutnya. Setelah proses pembelajaran tune up engine selesai guru melakukan tes terhadap siswa dan guru menilainya.

Kegiatan selama pengerjaan tune up engine dilihat dari pencapaian kerja tune up engine yang dilakukan oleh siswa. Rata-rata pencapaian hasil pengerjaan tune up engine dari semua siswa adalah 37,75 . Setiap siswa memiliki pencapaian hasil kerja yang berbedabeda. Persentase masing-masing siswa dapat diketahui dengan cara, sebagai berikut:

1. Total skor ketercapaian tune up engine $(\mathrm{n})=56$

2. Misalkan siswa 1 , total skor $(f)=38$

3. Maka, persentase ketercapaian (\%): $\%=\frac{f}{n} \times 100=\frac{38}{56} \times 100=67,86 \%$

\section{PEMBAHASAN}

Rata-rata ketercapaian tune up engine berdasarkan SKKNI dari semua siswa adalah 37,75 , sedangkan persentase ketercapaian tune up engine dengan nilai tertinggi yaitu 73,2 $\%$ dan $71,4 \%$, nilai terendahnya adalah $64,28 \%$ dan $62,5 \%$. Perincian ketercapaian tune up engine setiap siswa dengan nilai tertinggi adalah 41 dan 40, nilai sedang adalah 38 dan 
39, sedangkan untuk nilai terendah yaitu 35. Pencapaian standar tune up engine berdasarkan SKKNI yang ditetapkan adalah 56, dilihat dari data yang didapat masih banyak indikator yang belum tercapai.

Mengikuti prosedur kesehatan dan keselamatan kerja. Semua siswa yang melaksanakan tune up engine mengikuti apa yang di instruksikan oleh instruktur atau guru. Semua siswa yang melaksanakan tune up engine mempersiapkan tools tune up (alat tangan dan alat ukur) yang akan digunakan pada saat tune up engine. Semua siswa yang melaksanakan tune up engine memilih tools apa saja yang digunakan untuk pembongkaran, pemeriksaan dan pemasangan pada saat tune up engine. Semua siswa yang melaksanakan tune up engine melakukan pengecekan oli level. Semua siswa yang melaksanakan tune up engine melakukan pengecekan kuantitas dan kualitas pelumas. Semua siswa yang melaksanakan tune up engine menjaga kebersihan area kerja. Semua siswa yang melaksanakan tune up engine tidak menggunakan fender cover, karena fender cover digunakan apabila tune up engine dilaksanakan pada unit kendaraan, sedangkan tune up engine yang dilaksanakan oleh siswa hanya pada engine stand. Semua siswa yang melaksanakan tune up engine tidak menggunakan steering wheel cover, karena steering wheel cover digunakan apabila tune up engine dilaksanakan pada unit kendaraan, sedangkan tune up engine yang dilaksanakan oleh siswa hanya pada engine stand. Semua siswa yang melaksanakan tune up engine tidak menggunakan floor matt, karena floor matt digunakan apabila tune up engine dilaksanakan pada unit kendaraan, sedangkan tune up engine yang dilaksanakan oleh siswa hanya pada engine stand.

Penggunaan dan pemeliharaan peralatan dan perlengkapan tempat kerja. Semua siswa yang melaksanakan tune up engine dapat melakukan test dan kalibrasi peralatan tune up engine dengan sendiri tanpa bantuan. Semua siswa yang melaksanakan tune up engine dapat menggunakan tools dan equipment dengan benar dan sesuai dengan SOP. Semua siswa yang melaksanakan tune up engine dapat menjaga kebersihan tools dan equipment yang digunakan pada saat tune up engine.

Pelaksanaan pemeliharaan/servis komponen. Semua siswa yang melaksanakan tune up engine menggunakan workshop manual tentang sistem katup sebagai pedoman saat melakukan pemeriksaan dan penyetelan sistem katup. Semua siswa yang melaksanakan tune up engine melakukan pengecekan celah katup sesuai dengan SOP. Semua siswa yang melaksanakan tune up engine melakukan penyetelan celah katup sesuai dengan standar yang ditentukan. Dari 28 orang siswa yang melaksanakan tune up engine, hanya 14 orang 
siswa yang melaksanakan pengecekan terhadap momen baut kepala silinder, sedangakan 14 orang siswa lainnya tidak melaksanakan pengecekan momen baut kepala silinder.

Perbaikan sistem pengapian. Semua siswa yang melaksanakan tune up engine menggunakan workshop manual sebagai pedoman saat melaksanakan perbaikan sistem pengapian. Semua siswa yang melaksanakan tune up engine dapat melakukan pengecekan terhadap kondisi busi dan celah busi. Semua siswa yang melaksanakan tune up engine dapat melakukan pengecekan tahanan kabel busi. Semua siswa yang melaksanakan tune up engine dapat melakukan pengecekan tahanan kabel coil. Semua siswa yang melaksanakan tune up engine tidak dapat melakukan pengecekan distributor. Hal ini karena kurang disiplin pada saat pembelajaran dan pelaksanaan tune up engine. Semua siswa yang melaksanakan tune up engine dapat melakukan pengecekan terhadap rotor. Semua siswa yang melaksanakan tune up engine dapat melakukan pengecekan terhadap tutup distributor.

Dari 28 orang siswa yang melaksanakan tune up engine hanya 6 orang siswa yang melakukan pengecekan celah platina, sedangkan 22 orang siswa lainnya tidak melakukan pengecekan platina. Dari 28 orang siswa yang melaksanakan tune up engine hanya 5 orang yang melakukan penyetelan celah platina, sedangkan 23 orang siswa lainnya tidak melakukan penyetelan celah platina. Dari 28 orang siswa yang melaksanakan tune up engine hanya 6 orang yang melakukan pengecekan governor advance, sedangkan 22 orang siswa lainnya tidak melakukan pengecekan governor advance. Dari 28 orang siswa yang melaksanakan tune up engine hanya 7 orang siswa yang melakukan pengecekan vacuum advance, sedangkan 21 orang siswa lainnya tidak dapat melakukan pengecekan vacuum advance.

Pembacaan gambar teknik (wiring). Dari 28 orang siswa yang melaksanakan tune up engine hanya 18 orang siswa yang melakukan pengecekan tahanan primer dan sekunder coil, sedangkan 10 orang siswa lainnya tidak melakukan pengecekan tahanan primer dan sekunder.

Pengujian, pemeliharaan/servis dan penggantian baterai. Semua siswa yang melaksanakan tune up engine menggunakan workshop manual tentang pemeliharaan/servis dan penggantian baterai sebagai pedoman dalam melaksanakan pengujian, pemeliharaan/servis dan penggantian baterai. Semua siswa yang melaksanakan tune up engine dapat melakukan pengecekan berat jenis baterai dengan baik dan sesuai SOP. Semua siswa yang melaksanakan tune up engine dapat melakukan pengecekan tegangan pada baterai. Dari 28 orang siswa yang melaksanakan tune up engine hanya 11 orang siswa 
yang melakukan pemeriksaan terminal dan bodi (kotak) baterai, sedangkan 17 orang siswa lainnya tidak melakukan pemeriksaan terminal dan bodi (kotak). Semua siswa yang melaksanakan tune up engine dapat melakukan pemeriksaan jumlah air baterai. Semua siswa yang melaksanakan tune up engine menggunakan workshop manual tentang sistem bahan bakar bensin sebagai pedoman pada saat melakukan pemeliharaan/servis sistem bahan bakar bensin. Semua siswa yang melaksanakan tune up engine dapat melakukan pengecekan saringan udara. Dari 28 orang siswa yang melaksanakan tune up engine hanya 19 orang siswa yang melaksanakan pembersihan saringan udara, sedangkan 9 orang siswa lainnya tidak melakukan pembersihan saringan udara. Dari 28 orang siswa yang melaksanakan tune up engine hanya 6 orang siswa yang melakukan pengecekan saringan bahan bakar, sedangkan 22 orang siswa lainnya tidak melakukan pengecekan saringan bahan bakar. Dari semua siswa yang melaksanakan tune up engine, tidak ada satupun siswa yang dapat melakukan pembersihan saringan bahan bakar.

Pemeliharaan/servis sistem pendingin dan komponen-komponennya. Semua siswa yang melaksanakan tune up engine menggunakan workshop manual tentang sistem pendingin sebagai pedoman pada saat melaksanakan pemeliharaan/servis sistem pendingin dan komponen-komponennya. Semua siswa yang melaksanakan tune up engine tidak ada satupun siswa yang melakukan pengecekan tegangan fan belt. Dari 28 orang siswa yang melaksanakan tune up engine hanya 14 orang siswa yang melakukan pengecekan kebocoran radiator, sedangkan 14 orang siswa lainnya tidak melakukan pengecekan kebocoran radiator. Dari 28 orang siswa yang melaksanakan tune up engine hanya 3 orang siswa yang melakukan pengecekan tutup radiator, sedangkan 25 orang siswa lainnya tidak melakukan pengecekan tutup radiator. Dari 28 orang siswa yang melaksanakan tune up engine hanya 11 orang siswa yang melakukan pengecekan reservoir, sedangkan 17 orang siswa lainnya tidak melakukan pengecekan reservoir.

Penggunaan dan pemeliharaan alat ukur. Dari semua siswa yang melaksanakan tune up engine tidak ada satupun siswa yang dapat menggunakan engine analyzer. Semua siswa yang melaksanakan tune up engine dapat menggunakan timing light untuk mengecek ignition timing.

Pelaksanaan operasi penanganan secara manual (prosedur kerja). Semua siswa yang melaksanakan tune up engine menggunakan workshop manual tentang operasi penanganan secara manual (prosedur kerja) pada saat tune up engine. Dari 28 orang siswa yang melaksanakan tune up engine hanya 16 orang siswa yang melakukan pengecekan engine idle, sedangkan 12 orang siswa lainnya tidak melakukan pengecekan engine idle. Dari 28 
orang siswa yang melaksanakan tune up engine hanya 6 orang siswa yang melaksanakan pengecekan sudut $d w e l l$, sedangkan 22 orang siswa lainnya tidak melakukan pengecekan sudut $d w e l l$. Semua siswa yang melaksanakan tune up engine dapat melakukan pengecekan ignition timing dengan baik. Dari 28 orang siswa yang melaksanakan tune up engine hanya 6 orang siswa yang melakukan penyetelan ignition timing, sedangkan 22 orang siswa lainnya tidak melakukan penyetelan ignition timing.

Pemeliharaan/servis sistem kontrol emisi. Semua siswa yang melaksanakan tune up engine tidak ada yang menggunakan workshop manual tentang emisi gas buang. Semua siswa yang melaksanakan tune up engine, tidak ada yang dapat melakukan penyetelan putaran idle. Semua siswa yang melaksanakan tune up engine, tidak ada satupun siswa yang dapat memeriksa CO. Semua siswa yang melaksanakan tune up engine, tidak ada satupun siswa yang dapat memeriksa HC. Semua siswa yang melaksanakan tune up engine, tidak ada satupun siswa yang dapat menyetel IMAS/ISAS. Kontribusi komunikasi di tempat kerja. Semua siswa yang melaksanakan tune up engine dapat melakukan konfirmasi dan komunikasi terhadap atasan/instruktur tentang pekerjaannya.

\section{KESIMPULAN}

Keimpulan dari penelitian ini, yaitu hasil belajar siswa pada kompetensi tune up engine berdasarkan SKKNI menunjukkan hasil yang kurang baik, karena tidak ada satupun siswa yang dapat mencapai indikator tune up engine berdasarkan SKKNI.

\section{REFERENSI}

Arifin, Z. (2013). Evaluasi Pembelajaran. Bandung: PT. Remaja Rosdakarya.

Arikunto, S. \& Jabar, A., C. S. (2010). Evaluasi Program Pendidikan: Pedoman Teoritis Bagi Mahasiswa dan Praktisi Pendidikan. Jakarta: Bumi Aksara.

Bintoro. (2013). Pemeliharaan Mesin Kendaraan Ringan. Jakarta: Kementrian Pendidikan \& Kebudayaan.

Ratnawulan dan Rusdiana. (2015). Evaluasi Pembelajaran. Bandung: CV Pustaka Setia. Widoyoko, E. P. (2016). Evaluasi Program Pembelajaran. Yogyakarta: Pustaka Pelajar. 